University of Nebraska - Lincoln

DigitalCommons@University of Nebraska - Lincoln

Faculty Publications from the Harold W. Manter Laboratory of Parasitology

4-1969

\title{
Acanthocephala of Louisiana Picidae with Description of a New Species of Mediorhynchus
}

\author{
Brent B. Nickol \\ University of Nebraska - Lincoln, bnickol1@unl.edu
}

Follow this and additional works at: https://digitalcommons.unl.edu/parasitologyfacpubs

Part of the Parasitology Commons

Nickol, Brent B., "Acanthocephala of Louisiana Picidae with Description of a New Species of Mediorhynchus" (1969). Faculty Publications from the Harold W. Manter Laboratory of Parasitology. 358. https://digitalcommons.unl.edu/parasitologyfacpubs/358

This Article is brought to you for free and open access by the Parasitology, Harold W. Manter Laboratory of at DigitalCommons@University of Nebraska - Lincoln. It has been accepted for inclusion in Faculty Publications from the Harold W. Manter Laboratory of Parasitology by an authorized administrator of DigitalCommons@University of Nebraska - Lincoln. 


\title{
ACANTHOCEPHALA OF LOUISIANA PICIDAE WITH DESCRIPTION OF A NEW SPECIES OF MEDIORHYNCHUS*
}

\author{
Brent B. Nickol \\ Department of Zoology, The University of Nebraska, Lincoln, Nebraska 68508
}

ABSTRACT: One hundred eighty-three woodpeckers of eight species collected in Louisiana were examined for Acanthocephala. Only the red-bellied woodpecker, Centurus carolinus, was infected. One of 53 was parasitized by an immature specimen of Mediorhynchus grandis; three by Centrorhynchus spinosus; 12 by Mediorhynchus centurorum sp. $n$. The new species of Mediorhynchus is distinguished by a trunk which is very narrow in the anterior $3 \mathrm{~mm}$, but is suddenly expanded farther posteriad. Proboscis armature of 22 to 24 slightly spiral rows of six hooks and four or five spines each differs from all other species of the genus except $M$. corcoracis and $M$. emberizae. The maximum number of proboscis spines in $M$. centurorum matches the minimum number for $M$. corcoracis, but usually specimens of $M$. corcoracis possess more spines than those of $M$. centurorum. $M$. corcoracis also has larger eggs. The new species is distinguished from M. emberizae by males with cement glands widely separated from posterior testes and lemnisci which end before reaching the level of the anterior testes. C. spinosus and $M$. grandis have not previously been reported from Picidae or from Louisiana.

Results of a survey of Acanthocephala of Louisiana birds conducted from 1964 through 1966 were submitted to the Graduate Faculty of The Louisiana State University Agricultural and Mechanical College in partial fulfillment of the requirements for the degree of Doctor of Philosophy. Most of the specimens used in the present study were collected during that survey. Forty-nine acanthocephalans recovered from 12 of 53 red-bellied woodpeckers, Centurus carolinus, closely resembled Mediorhynchus papillosus Van Cleave, 1916. Re-evaluation of those specimens and additional collection data have made it apparent that the worms collected from C. carolinus represent an undescribed species of Mediorhynchus. Three red-bellied woodpeckers were infected with Centrorhynchus spinosus and one with $M$. grandis. No mixed infections were found. Colaptes auratus (5), Dendrocopos borealis (4), D. pubescens (40), D. villosus (4), Dryocopus pileatus (3), Melanerpes erythrocephalus (26), and Sphyrapicus varius (48) were not infected with acanthocephalans. All measurements are in microns with averages in parentheses unless otherwise stated. Numbers in parentheses following names of birds indicate number examined.

\footnotetext{
Mediorhynchus centurorum sp. $n$. (Figs. 1-8)

\section{Description}

With characters of the genus Mediorhynchus. Body elongate and ribbonlike; males 17 to $32 \mathrm{~mm}$

Received for publication 22 November 1968.

* Studies from the Department of Zoology, University of Nebraska, No. 402.
}

(22) long, females 23 to $46 \mathrm{~mm}$ (35) long. Trunk with pronounced constriction 2 to $3.5 \mathrm{~mm}$ long and 350 wide slightly posterior to junction with neck. Following constricted region, trunk abruptly dilated to nearly uniform width, 1.0 to $1.8 \mathrm{~mm}(1.2)$, and slightly tapered at posterior extremity. No pseudosegmentation, but main lacunar canals with regular prominent lateral branches. Proboscis in shape of truncated cone, occasionally almost cylindrical; 571 to 744 (623) long, 192 to 240 (222) wide at apex, 336 to $542(412)$ wide at level of proboscis receptacle insertion, and 370 to 624 (474) wide at base; armed anteriorly with 22 to 24 slightly spiral rows of 6 hooks each and posteriorly with 22 to 24 rows of 4 or 5 spines each. Largest hook roots 39 to 46 (43) long, 6 to 10 (9) wide anteriorly and expanded posteriorly to circular, trapezoidal, or elongate disc 12 to 22 (16) wide. Thorns of hooks 38 to 46 (40) long, spines 29 to 34 (31) long. Each hook and spine surrounded by a papilla. Papillae around hooks and spines vary in height and prominence. Neck 192 to 258 (208) long, with pair of lateral sensory pits about 12 behind last spines. Proboscis receptacle 0.9 to $1.3 \mathrm{~mm}$ long, with pyramid-shaped ganglion, about 250 long and 90 wide, in posterior half located at about the level of neck-trunk boundary. Lemnisci 6.1 to $7.9 \mathrm{~mm}$ (6.7) long in males, 9.7 to $12.2 \mathrm{~mm}$ (10.1) long in females; about 1.3 wide in both sexes; well separated from anterior margin of front testis. Males with 2 spindle-shaped testes about equal in size, arranged in tandem, 2.20 to 3.45 $\mathrm{mm}$ (2.57) long and 644 to 1,010 (791) wide. Testes widely separated from each other and from group of eight pyriform cement glands. Cement glands unequal in size 326 to 768 (398) at widest point. Entire male reproductive system usually in posterior half of trunk occupying $43 \%$ to $49 \%$ of trunk length, occasionally up to $53 \%$. Female reproductive system from anterior edge of uterine bell to genital pore occupies 3.0 to $4.5 \%$ of trunk. Eggs 41 to 48 (46) long and 24 to 29 (27) wide when measured through body wall or removed 


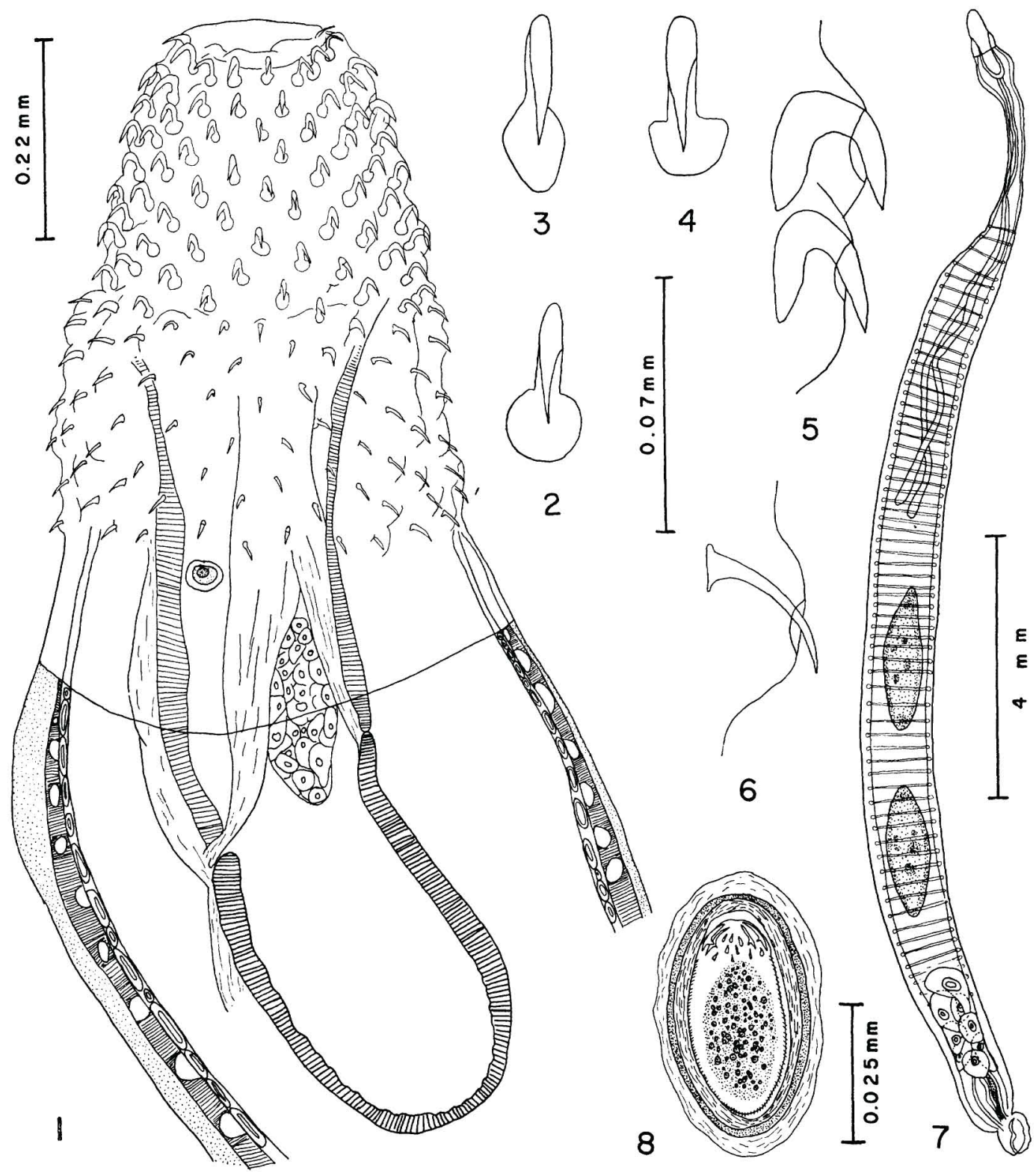

Figures 1-8. Camera lucida drawings of Mediorhynchus centurorum sp. $\mathrm{n}$. Projection between Figure 2 and Figure 5 applies equally to Figures 2-6. 1. Anterior end of female. 2-4. Typical hooks showing three different root shapes found in a single specimen. 5. Typical hooks, lateral view. 6. Spine, lateral view. 7. Male, lateral view. 8. Egg, removed from body cavity.

from body cavity of fixed females. Eggs shed by living female in tap water, 42 by 26.

Type host: Centurus carolinus.

Type locality: Louisiana, Iberville Parish (east side of Mississippi River), 18 miles $S$ of Baton Rouge.

Type specimens: USNM Helm. Coll. holotype male No. 71415 , allotype female No. 71417 , paratype No. 71416.

\section{Remarks}

A long, prominent constricted region of the trunk distinguishes Mediorhynchus centurorum from all other species of the genus (Fig. 7). $M$. centurorum penetrates deeply into the intestinal wall of its host causing a nodule to bulge into the coelom. Each nodule, about 
$4 \mathrm{~mm}$ long and $2 \mathrm{~mm}$ in diameter, contained the proboscis, neck, and foretrunk of a single acanthocephalan. Intestinal musculature at the nodule base was always constricted tightly around the trunk at a point corresponding to the constriction of the parasite. Even though the characteristic trunk constriction of $M$. centurorum is probably a result of compression by intestinal muscles of the host, it remains unaffected when the acanthocephalan is placed in tap water to force proboscis evagination. Other species of Mediorhynchus have not been found to cause nodules in the host intestine and a specimen of $M$. grandis did not do so when parasitizing Centurus carolinus. Two mature females of $M$. centurorum had completely penetrated their hosts' intestines and had anterior ends extending free into the coelom.

Mediorhynchus centurorum also differs from all other species of the genus except $M$. corcoracis Johnston and Edmonds, 1951, and $M$. emberizae (Rudolphi, 1819) in number and arrangement of proboscis hooks and spines.

$M$. corcoracis parasitizes members of the Grallinidae and Corvidae in Australia and as described by Johnston and Edmonds (1951), is slightly larger in size and has much larger eggs than $M$. centurorum. M. corcoracis possesses a proboscis with 120 to 144 spines on the posterior portion while corresponding spines of $M$. centurorum number 88 to 120 . Even though the maximum number of spines in $M$. centurorum matches the minimum number for $M$. corcoracis, the latter usually possess more spines than $M$. centurorum.

$M$. emberizae males are only 6 to $8 \mathrm{~mm}$ long, possess lemnisci which reach the level of the anterior testis, and do not have cement glands widely separated from the posterior testis (Meyer, 1932).

Travassos (1923) did not distinguish between proboscis hooks and spines in his description of $M$. oswaldocruzi and likely his description of "ganchos" refers only to the hooks on the distal portion. In that case $M$. oswaldocruzi possesses hooks of about the same size, number, and arrangement as M. centurorum. According to Meyer (1932), the trunk of $M$. oswaldocruzi is expanded at the anterior end and the proboscis is only $430 \mu$ long in females and $290 \mu$ long in males. This is a different trunk shape and much shorter proboscis than possessed by $M$. centurorum .

Since proboscis hooks, an important feature in distinguishing species of Acanthocephala, are frequently not arranged in definite rows and are often obscured by cuticular elevations in Mediorhynchus, features by which species of the genus could be distinguished were reevaluated by Van Cleave (1947). He concluded that size and shape of hook roots, readily observed, were important specific characters. In these features and in possession of papillae around hooks and spines, M. centurorum closely resembles $M$. papillosus. Hook roots of $M$. centurorum are only slightly longer than those of $M$. papillosus and many have circular basal discs characteristic of $M$. papillosus. The proboscis of $M$. centurorum, however, possesses hook roots with bases of three different shapes. Figures 2-4 illustrate adjacent hooks on the proboscis of a single specimen. In addition to the typical circular disc of $M$. papillosus (Fig. 2), roots with more elongated discs (Fig. 3) typical of $M$. grandis and $M$. robustus also occur. A third basal disc shape, more trapezoidal and unlike any described from a North American species, also occurs (Fig. 4).

Mediorhynchus centurorum differs from $M$. papillosus in two other respects. Schmidt and Canaris (1967) were the first to describe lateral sensory pits on the neck of any species of Mediorhynchus. Examination of a large number of $M$. papillosus from Louisiana and "type female" USNM Helm. Coll. No. 6320 Hassall Collection revealed that similar pits occur on the neck of $M$. papillosus about $43 \mu$ behind the last proboscis spines. Sensory pits of the neck of $M$. centurorum are usually less than $15 \mu$ and never more than $20 \mu$ behind last spines.

Although not mentioned in the description, Van Cleave (1916) illustrated lemnisci of $M$. papillosus extending to the level of the anterior testis. In $M$. centurorum they do not extend that far (Fig. 1).

\section{Centrorhynchus spinosus (Kaiser, 1893)}

One male and four female specimens of Centrorhynchus spinosus were collected from three red-bellied woodpeckers. They do not differ from the description of the species as emended by Van Cleave $(1916,1924,1940)$. 


\section{Mediorhynchus grandis Van Cleave, 1916}

One immature female specimen of Mediorhynchus grandis was collected from a redbellied woodpecker. With the exception of growth to $4 \mathrm{~mm}$ in length, development had not progressed noticeably beyond the cystacanth stage as described by Moore (1962).

\section{DISCUSSION}

Species of Mediorhynchus parasitize many birds, but only two, M. micracanthus and $M$. robustus, have been reported from any species of Picidae. According to Florescu (1941), M. micracanthus frequently parasitizes woodpeckers and there is one report (Van Cleave, 1947) of $M$. robustus from a woodpecker. In North America no acanthocephalan species has been reported regularly to parasitize woodpeckers. In Louisiana, however, $23 \%$ of the Centurus carolinus examined were parasitized by $M$. centurorum. Infected individuals harbored from one to 13 acanthocephalans with the mode being two and only two birds having more than three acanthocephalans.

The one immature specimen of $M$. grandis taken from a red-bellied woodpecker is thought to have been an accidental infection since it usually occurs in meadowlarks. This is further substantiated by the fact that $M$. grandis was found in about $60 \%$ of the Sturnella magna taken from a field adjacent to the woods from which the infected woodpecker was collected.

Mediorhynchus centurorum appears to have a high degree of host specificity. Nine hundred birds of 68 species in 30 families from Louisiana were examined, and even though many of the birds came from the same or similar habitats, $M$. centurorum was found only in Centurus carolinus. Seventy-six of the 900 individuals divided among 20 species were collected from a single, small wooded area, about 5 acres, located 18 miles south of Baton Rouge, Louisiana. $M$. centurorum was recovered from 10 of 16 C. carolinus, but not from any other species. Other Picidae examined from this collecting site were Colaptes auratus (2), Dendrocopos pubescens (9), D. villosus (1), and Sphyrapicus varius (13). Dr. Gerald D. Schmidt, Colorado State College, Greeley, was kind enough to loan two specimens from the collection of Dr. Robert L. Rausch, U. S. Public Health Service, Anchor- age, Alaska, which had been recovered from woodpeckers in Worth County, Georgia. These two specimens were from Centurus carolinus and are conspecific with $M$. centurorum. None of six red-bellied woodpeckers collected in eastern Nebraska was parasitized by Acanthocephala.

Several species of Centrorhynchus have been reported from Picidae, but even though $C$. spinosus has a low degree of host specificity (Read, 1950) it has never before been reported from a woodpecker. All of the Centurus carolinus parasitized by C. spinosus were from a single wooded area near Robert, Louisiana. Never more than two specimens of C. spinosus were found in any single woodpecker. At the same collecting site birds of prey, Strix varia, Buteo platypterus, and $B$. lineatus, often were parasitized by large numbers of $C$. spinosus, and on several occasions more than 50 cystacanths were recovered from mesenteries of individual snakes, Thamnophis proximus. Van Cleave (1947) postulated that the low intensity of Mediorhynchus infections, usually only one or two worms per host, was due to lack of a paratenic host to concentrate infective larvae. This may also explain the low intensity of C. spinosus in woodpeckers while birds of prey in the same area are heavily infected. Presumably the woodpeckers acquired their infections directly from an arthropod intermediate host while birds of prey became infected by feeding upon infected paratenic hosts, such as Thamnophis proximus.

\section{ACKNOWLEDGMENTS}

The author is indebted to Drs. Kenneth C. Corkum of Louisiana State University and Francis C. Rabalais of Bowling Green State University for assistance in collecting avian hosts.

\section{LITERATURE CITED}

Florescu, B. 1941. Mediorhynchus micracanthus (Rudolphi, 1819) in Rumänien. Compt. Rend. Acad. Sci. Roumanie 5: 69-74.

Johnston, T. H., AND S. J. EDmonds. 1951. Australian Acanthocephala No. 8. Tr. Roy. Soc. S. Austral. 74: 1-5.

Meyer, A. 1932. Acanthocephala. Bronn's Klassen und Ordnungen des Tierreichs 4 (2, 2, 1) : $332 \mathrm{p}$.

Moone, D. V. 1962. Morphology, life history, and development of the acanthocephalan 
Mediorhynchus grandis Van Cleave, 1916. J. Parasit. 48: 76-86.

ReaD, C. P. 1950. The rat as an experimental host of Centrorhynchus spinosus (Kaiser, 1893), with remarks on host specificity of the Acanthocephala. Tr. Am. Micr. Soc. 69: 179-182.

Schmidt, G. D., and A. G. Canaris. 1967. Acanthocephala from Kenya with descriptions of two new species. J. Parasit. 53: 634-637.

Travassos, L. 1923. Gigantorhinchidios novos. Folha Medica 4: 12.

Van Cleave, H. J. 1916. Acanthocephala of the genera Centrorhynchus and Mediorhynchus (new genus) from North American birds. Tr. Am. Micr. Soc. 35: 211-232.

1924. A critical study of the Acanthocephala described and identified by Joseph Leidy. Proc. Acad. Nat. Sci. Philadelphia 76: 279-334.

1940. The Acanthocephala collected by the Allan Hancock Pacific Expedition, 1934. Rep. Hancock Pacific Expedition (193237) $2: 501-527$.

. 1947. The acanthocephalan genus $M e$ diorhynchus, its history and a review of the species occurring in the United States. J. Parasit. 33: 297-315. 